\title{
ANÁLISE DOS MÉTODOS TRADICIONAIS PARA ESCOLHA DA PERIODICIDADE NA CALIBRAÇÃO DE INSTRUMENTOS: ESTUDO DE CASO
}

\author{
Camila Ferreira Trindadde ${ }^{1}$ \\ Camila Mayra Aparecida Santos ${ }^{2}$ \\ André Silva Chaves ${ }^{3}$
}

Resumo: A calibração em instrumentos de medições deve ser uma atividade normal de produção tendo em vista que para assegurar uma boa qualidade no produto ela é indispensável. Cada organização define uma periodicidade para calibrar seu equipamento que melhor se enquadre nos termos financeiros e de qualidade. Os instrumentos podem ser submetidos a influências externas diferentes, tais como: temperatura, umidade, tempo de uso, maneira de como o instrumento é manuseado, fazendo necessária a utilização de um ou vários métodos de calibração dependendo das condições que se encontram. Sendo assim, muitas empresas submetem seus instrumentos à calibração periódica para manter a confiabilidade nas medições, segurança nos resultados e controle nos processos. Este artigo tem como objetivo através de um estudo de caso, apresentar cinco métodos de calibração para melhor definir a periodicidade nas calibrações dentro de empresas e descrever o processo utilizado por duas empresas de ramos diferentes. Palavras-chave: Calibração; Periodicidade; Qualidade; Instrumentos de medição.

\footnotetext{
1 Engenharia de Produção/FEPI - Centro Universitário de Itajubá, Brasil. E-mail: camilaferreira.trindade@gmail.com.

2 Engenharia de Produção/FEPI - Centro Universitário de Itajubá, Brasil. E-mail: cmasantos@hotmail.com.br.

${ }^{3}$ Engenharia de Produção/FEPI - Centro Universitário de Itajubá, Brasil. E-mail: as.chaves@yahoo.com.br.
} 